\title{
The effect of perceived forgetfulness on quality of life in older adults: a qualitative review
}

Citation for published version (APA):

Mol, M. E. M., Carpay, M., Ramakers, I. H. G. B., Rozendaal, N., Verhey, F. R. J., \& Jolles, J. (2007). The effect of perceived forgetfulness on quality of life in older adults: a qualitative review. International Journal of Geriatric Psychiatry, 22(5), 393-400. https://doi.org/10.1002/gps.1686

Document status and date:

Published: 01/01/2007

DOI:

10.1002/gps.1686

Document Version:

Publisher's PDF, also known as Version of record

\section{Please check the document version of this publication:}

- A submitted manuscript is the version of the article upon submission and before peer-review. There can be important differences between the submitted version and the official published version of record.

People interested in the research are advised to contact the author for the final version of the publication, or visit the DOI to the publisher's website.

- The final author version and the galley proof are versions of the publication after peer review.

- The final published version features the final layout of the paper including the volume, issue and page numbers.

Link to publication

\footnotetext{
General rights rights.

- You may freely distribute the URL identifying the publication in the public portal. please follow below link for the End User Agreement:

www.umlib.nl/taverne-license

Take down policy

If you believe that this document breaches copyright please contact us at:

repository@maastrichtuniversity.nl

providing details and we will investigate your claim.
}

Copyright and moral rights for the publications made accessible in the public portal are retained by the authors and/or other copyright owners and it is a condition of accessing publications that users recognise and abide by the legal requirements associated with these

- Users may download and print one copy of any publication from the public portal for the purpose of private study or research.

- You may not further distribute the material or use it for any profit-making activity or commercial gain

If the publication is distributed under the terms of Article $25 \mathrm{fa}$ of the Dutch Copyright Act, indicated by the "Taverne" license above, 


\title{
The effect of perceived forgetfulness on quality of life in older adults; a qualitative review
}

\author{
Martine Mol, Margot Carpay, Inez Ramakers, Nico Rozendaal, Frans Verhey and Jelle Jolles* \\ Brain and Behaviour Institute, Department of Psychiatry and Neuropsychology, Maastricht University, Netherlands
}

\begin{abstract}
SUMMARY
Background Approximately 50\% of older individuals perceive themselves as being forgetful.

Objective The objective of this review is to get an overview of previous research on the relation between perceived forgetfulness (in the absence of objective memory deficit) and quality of life in older individuals. Findings in previous research might be a starting point for further research and possible future interventions.

Methods Scientific papers that investigated the relation between subjective memory complaints and quality of life were searched. Two independent raters scored the articles on their methodology. The methodological quality was taken into account when conclusions were drawn.

Results The literature search resulted in 682 articles, of which five studies met the inclusion criteria. Although the five studies differed in their methodology, the findings of the methodologically adequate studies show a relation between memory complaints and a diminished quality of life in the elderly.

Conclusions The negative impact that subjective memory complaints can have on quality of life makes it important to acknowledge forgetfulness as a serious issue in the life of older individuals. However, more research is needed to explore the relationship between subjective memory complaints and quality of life, also with regard to the influence of depression and objective memory performance. Copyright (C) 2006 John Wiley \& Sons, Ltd.
\end{abstract}

KEY WORDS - memory complaints; well-being; quality of life; forgetfulness; literature search; review

\section{INTRODUCTION}

Complaints about forgetfulness and diminishing memory function are very common among older people (Blazer et al., 1997; Ponds et al., 1997). The prevalence of memory complaints in communitybased samples of older people varies from approximately $25 \%$ to over $50 \%$ (Jonker et al., 2000). In the Maastricht Aging Study the prevalence of forgetfulness in the 55-65 age group was $41 \%$, and in the $70-85$ age group the prevalence was $52 \%$ (Ponds et al., 1997). Approximately $60 \%$ of the middle-aged individuals perceive much hindrance from their forgetfulness, and approximately $70 \%$ are very

*Correspondence to: J. Jolles, Brain and Behaviour Institute, Department of Psychiatry and Neuropsychology, Maastricht University, PO Box 616, 6200 MD Maastricht, The Netherlands.

E-mail: j.jolles@np.unimaas.nl

Copyright (C) 2006 John Wiley \& Sons, Ltd. worried about it (Commissaris et al., 1998). However, not much attention is given to the impact that memory complaints, even when only subjective, can have on someone's quality of life, although complaints about forgetfulness and diminishing memory function are very common among older people. An overview of previous research is needed to get insight into the relation between perceived forgetfulness and a person's quality of life. Findings in previous research might be a starting point for further research and possible future interventions.

In order to get an overview of the results of previous studies on the relation between being forgetful and quality of life in older people, we performed a search in the relevant literature. The identified studies were scored on their methodological quality, which was taken into account when conclusions were drawn. Forgetfulness and subjective memory complaints were used interchangeably in this review. Being forgetful in 
this paper was regarded as having subjective memory complaints in the absence of an objective deficit. Furthermore, the focus of quality of life in this review was to look at a broad span of quality of life, including life satisfaction and well-being. Symptoms of depression and anxiety were included when it was part of the quality of life or well-being scale.

\section{METHODS}

\section{Literature search}

The publications involved in this study were retrieved by computerized searches of PubMed (1966 to February 2006), PsycINFO (1966 to February 2006) and Embase (1986 to February 2006). The following search strategy and key words were used: ['age' or 'elderly' or 'aging'] and ['quality of life' or 'wellbeing'] and ['memory' or 'subjective memory complaints' or 'memory complaints' or 'forgetfulness']. The databases were also searched with different spelling forms of these words. After obtaining all relevant papers, the references of these studies were hand searched to find additional potentially relevant papers.

To be selected for this review, studies had to meet all of the following criteria: (a) the participants examined in the study were healthy older people with subjective memory complaints, but with no objective cognitive disorder such as dementia; (b) the study measured the relation between subjective memory complaints and the participants' quality of life or well-being; (c) the study was not an intervention study, to prevent that the intervention would confound the relation between subjective memory complaints and quality of life. However, articles that examined a cross-sectional relation on baseline-date were included; (d) the article was a full report of the study; (e) the paper was published in English. The studies that were expected to meet all the inclusion criteria on the basis of the title or, if available, the abstract, were obtained.

\section{Quality assessment of selected studies}

The methodological quality was assessed according to standardized methodological criteria (De Vet et al., 1997). A list of 13 criteria divided into four methodological items of an observational study was constructed, including research population and study design, measurement instruments, and data analyses and presentation (Appendix 1). Maximum scores were determined beforehand, with more important criteria receiving relatively higher scores. A maximum score of 43 could be obtained per study.

Two raters, who were not involved in the development of the methodological criteria list, independently applied the criteria to all selected articles. The raters received a brief instruction to prevent misinterpretation of the criteria. Such an instruction increases the consistency between the raters, which might increase the reliability of this qualitative review (Lipsey and Wilson, 2001). To prevent bias, all reviewed articles had the author(s), journal, year of publishing, name and location of institute, and acknowledgements removed. Inconsistencies in the assessments of both raters were identified and discussed during a consensus meeting. The final scores for the papers were then summed. The studies were ranked according to these total scores, resulting in a hierarchical list in which a higher score means a higher considered methodological quality of the study. Methodological ratings were based solely on material presented in the article. Some studies may therefore have been under-rated if authors failed to mention important details of the study.

\section{RESULTS}

\section{Literature search}

The search resulted in 682 articles (292 in Pubmed, 188 in PsychINFO, and 202 in Embase). These 682 articles were searched to establish whether they met the inclusion criteria on the basis of their title and abstract. This resulted in the identification of 15 articles (Capsi and Elder, 1986; Steen et al., 1987; Derouesné et al., 1989; Deeg et al., 1992; McDougall, 1994; Neri et al., 1995; Wolters et al., 1996; Bazargan and Bazargan, 1997; Kim and Mueller, 1997; Commissaris et al., 1998; Derouesné et al., 1999; Verhaeghen et al., 2000; McDougall et al., 2003; Starr et al., 2003; Bryan and Calvaresi, 2004). Subsequently, these 15 articles were obtained and nine of these 15 articles were found not to meet our inclusion criteria. Three articles did not assess the impact of subjective memory complaints on the participants' quality of life (Neri et al., 1995; Wolters et al., 1996; Bryan and Calvaresi, 2004). Four articles measured objective memory, but did not measure subjective memory complaints (Capsi and Elder, 1986; Steen et al., 1987; Deeg et al., 1992; Starr et al., 2003). Two articles did not measure quality of life (McDougall, 1994; McDougall et al., 2003). 
Six articles met the inclusion criteria. One of these studies (Kim and Mueller, 1997) was a case report. Four cases were selected from a sample of 107 Korean American older adults, with the specific intent of providing a more comprehensive understanding of the relationship between memory self-efficacy and wellbeing. Each case showed a unique pattern of interplay of these cognitive and affective variables. Two cases support the relationship between memory complaints and quality of life, while the other two contradicted the relationship. However, the number of cases studied is too small and the selection method is too prejudiced to generalize the findings of this study. We therefore chose to exclude the article from this review. Ultimately, five articles were included in this review (Derouesné et al., 1989; Bazargan and Bazargan, 1997; Commissaris et al., 1998; Derouesné et al., 1999; Verhaeghen et al., 2000) (see also Table 1).

\section{Methodological quality}

The raters' scores were similar on 35 of the 65 aspects (13 aspects and five articles; $54 \%$ ). The results of the methodological assessment can be found in Table 2. All five papers presented here scored above 60\%; (Derouesné et al., 1989; Bazargan and Bazargan, 1997; Commissaris et al., 1998; Derouesné et al., 1999; Verhaeghen et al., 2000). The mean methodological quality score was 31 ( $72 \%$ of the total score of 43). The scores ranged between $26(60 \%)$ and $34(79 \%)$, showing that the studies were of moderate to high methodological quality. The most common shortcomings were the description of the study population and design. Descriptions of the instruments used to measure subjective memory and quality of life were adequate, as were the descriptions of the statistical analysis and the presentation of the data.

\section{Relation between subjective memory and quality of life}

Table 1 presents the study characteristics of the five included studies. There was a wide variety in study design and instruments used to measure the participants' subjective memory complaints and well-being. One study used life satisfaction scales to measure quality of life (Commissaris et al., 1998), three studies used well-being questionnaires (Derouesné et al., 1989; Bazargan and Bazargan, 1997; Derouesné et al., 1999) and one study used a life satisfaction scale in combination with a depression scale as a measure of well-being (Verhaeghen et al., 2000). Subjective memory function was measured with subjective memory scales (Derouesné et al., 1989; Derouesné et al., 1999), memory functioning questionnaires (Bazargan and Bazargan, 1997), meta-memory scales (Verhaeghen et al., 2000) and a single item question (Commissaris et al., 1998).

All five identified studies reported a relation between subjective memory problems and lower quality of life in older adults (Derouesné et al., 1989; Bazargan and Bazargan, 1997; Commissaris et al., 1998; Derouesné et al., 1999; Verhaeghen et al., 2000). The first study (Derouesné et al., 1999) found a correlation of $r=-0.33(p<0.001)$ in the young $(20$ 49 years $)$ and $r=-0.28(p<0.001)$ in the older $(49$ 85 years) age group between subjective memory complaints and well-being. They conducted a multivariate stepwise regression and found that well-being $\left(F_{2,180}=14.7\right)$ together with anxiety $\left(F_{1,181}=22.6\right)$ were related to subjective memory complaints $(p<0.001)$. The second study (Commissaris et al., 1998) compared participants who considered themselves forgetful with participants who had no complaints about their memory. The average score of the forgetful participants on the questionnaire to measure satisfaction with life was 38.9 and that of the non-forgetful participants was 40.4 (range 15-45). After performing a $t$-test, it appeared that participants who were forgetful were less satisfied with life $(t=5.5, p<0.001)$. In the third study, an earlier study from Derouesné et al. (1989), they also found that memory complaints were strongly related with low scores in the well-being questionnaire. However, depression and not well-being was the unique variable related to severity of memory complaints. The mean score of participants with minor memory complaints on the questionnaire to measure well-being was $74.5( \pm 13.4)$ and of participants with major memory complaints was $68.8( \pm 16.2)$ (range $0-110)$. No values of the analysis were reported in the paper. The fourth study (Bazargan and Bazargan, 1997) found a correlation of $r=0.43 \quad(p<0.001)$ between selfreported memory functioning and well-being. They also analysed the predictive value of subjective memory complaints on measures of well-being and found that self-reported memory function was the strongest predictor of psychological well-being $(\beta=0.25, \quad p<0.001)$ after conducting multiple regression analysis. Finally, the fifth study (Verhaeghen et al., 2000) reported a path analysis performed with LISREL 8. In the final model, well-being received a total effect of 0.20 of the coping variable, 
Table 1. Characteristics of included studies

\begin{tabular}{|c|c|c|c|c|c|}
\hline Study & Sample & $\begin{array}{l}\text { Instruments measuring } \\
\text { memory complaints }\end{array}$ & $\begin{array}{c}\text { Instruments measuring } \\
\text { quality of life }\end{array}$ & Outcome & Relation \\
\hline $\begin{array}{l}\text { 1. Derouesné } \\
\text { et al., } 1999\end{array}$ & $\begin{array}{c}N=260 \\
\text { Age range; } 20-49 \\
\text { and } 49-85 \\
\text { Self-referrals } \\
\text { EC: GCS } \leq 90\end{array}$ & SMS & WBQ & $\begin{array}{l}\text { In the oldest age group, } \\
\text { a significant negative } \\
\text { correlation was found } \\
\text { between subjective memory } \\
\text { complaints and WBQ } \\
\text { (Pearson correlation }=-0.28, \\
p<0.01) \text {. Well-being as well } \\
\text { as anxiety were related to } \\
\text { subjective memory complaints } \\
(F 2,180=14.7 \text { and } F 1,181=22.6 \\
\text { respectively) }\end{array}$ & + \\
\hline $\begin{array}{l}\text { 2. Commissaris } \\
\text { et al., } 1998\end{array}$ & $\begin{array}{c}N=1971 \\
\text { Age range; } 25-85 \\
\text { Community based } \\
\text { EC: Dementia, overt } \\
\text { cerebrovascular disease }\end{array}$ & $\begin{array}{l}\text { Single-item } \\
\text { question }\end{array}$ & SWLS & $\begin{array}{l}\text { Participants who were forgetful } \\
\text { were less satisfied with life } \\
(t=5.5 ; p<0.01)\end{array}$ & + \\
\hline $\begin{array}{l}\text { 3. Derouesné } \\
\text { et al., } 1989\end{array}$ & $\begin{array}{c}N=367 \\
\text { Age range; } 50-80 \\
\text { Self-referrals } \\
\text { EC: Organic cerebral } \\
\text { disorder }\end{array}$ & SMS & WBQ & $\begin{array}{l}\text { Severity of memory complaints } \\
\text { was strongly related to low scores } \\
\text { in the WBQ. However, depression } \\
\text { and not well-being was the unique } \\
\text { variable related to severity of } \\
\text { memory complaints }\end{array}$ & + \\
\hline $\begin{array}{l}\text { 4. Bazargan and } \\
\text { Bazargan, } 1997\end{array}$ & $\begin{array}{l}\quad N=998 \\
\text { Age range; 62-99 } \\
\text { Community based }\end{array}$ & MFQ & PGC Morale Scale & $\begin{array}{l}\text { Memory functioning is } \\
\text { significantly related to } \\
\text { psychological well-being } \\
(r=0.43, p<0.001) \text {. } \\
\text { Memory functioning was } \\
\text { the best predictor of } \\
\text { psychological well-being } \\
(\beta=.25, p<0.001)\end{array}$ & + \\
\hline $\begin{array}{l}\text { 5. Verhaeghen } \\
\text { et al., } 2000\end{array}$ & $\begin{array}{l}\quad N=179 \\
\text { Age range; 49-97 } \\
\text { Community based }\end{array}$ & MIA & $\begin{array}{l}\text { Combination of LSI } \\
\text { and CES-D }\end{array}$ & $\begin{array}{l}\text { Coping with memory } \\
\text { complaints and experiencing } \\
\text { low frequency of complaints } \\
\text { (high memory capacity) } \\
\text { is related to a better well-being } \\
\text { (relation in model } 0.20 \text { and } \\
0.18 \text { respectively) }\end{array}$ & + \\
\hline
\end{tabular}

CES-D = Center for Epidemiologic Studies-Depression-Scale; EC=Exclusion Criteria; GCS=Global Cognitive Score; LSI = Life Satisfaction Index; MCI = Memory Controllability Inventory; MFQ = Memory Functioning Questionnaire; MIA = Meta-memory in Adulthood; $\quad \mathrm{PGC}=$ Philadelphia Geriatric Centre; $\mathrm{SMS}=$ Subjective Memory Scale; SWLS=Satisfaction with Life Scale; $\mathrm{WBQ}=$ Well-being Questionnaire; $+=$ Relation found between forgetfulness and memory complaints.

0.14 of the locus of control variable, 0.12 of the capacity variable, 0.10 of the change variable, 0.06 of the seriousness variable and 0.03 of the anxiety variable. The total effect of each of these variables on well-being is the sum of all direct and indirect effects from the variable to well-being through all possible paths linking the two.

In summary, all studies reported a relation between subjective memory complaints and lower quality of life. In addition, one study reported that depression and not well-being was the unique variable related with severity of memory complaints.

\section{DISCUSSION}

Five papers on the relation between subjective memory complaints and quality of life fulfilled the 
Table 2. Methodological quality of the five included studies

\begin{tabular}{|c|c|c|c|c|c|c|c|c|c|c|c|c|c|c|c|}
\hline Criterion & $\mathrm{A}_{1}$ & $\mathrm{~A}_{2}$ & $\mathrm{~A}_{3}$ & $\mathrm{~A}_{4}$ & $\mathrm{~A}_{5}$ & $\mathrm{~B}_{1}$ & $\mathrm{~B}_{2}$ & $\mathrm{C}_{1}$ & $\mathrm{C}_{2}$ & $\mathrm{D}_{1}$ & $\mathrm{D}_{2}$ & $\mathrm{D}_{3}$ & $\mathrm{D}_{4}$ & Total & $\%$ \\
\hline Max score & 6 & 6 & 2 & 6 & 2 & 3 & 2 & 3 & 2 & 3 & 2 & 2 & 4 & 43 & 100 \\
\hline \multicolumn{16}{|l|}{ Incl. studies: } \\
\hline 1. Derouesné et al., 1999 & 6 & 3 & 1 & 4 & 0 & 3 & 2 & 3 & 2 & 3 & 2 & 1 & 4 & 34 & $79 \%$ \\
\hline 2. Commissaris et al., 1998 & 6 & 2 & 1 & 6 & 0 & 2 & 2 & 3 & 2 & 3 & 0 & 2 & 4 & 33 & $77 \%$ \\
\hline 3. Derouesné et al., 1989 & 6 & 3 & 2 & 4 & 0 & 3 & 2 & 0 & 2 & 3 & 1 & 2 & 4 & 32 & $74 \%$ \\
\hline 4. Bazargan and Bazargan, 1997 & 1 & 3 & 2 & 6 & 0 & 3 & 2 & 3 & 2 & 3 & 0 & 1 & 4 & 30 & $70 \%$ \\
\hline 5. Verhaeghen et al., 2000 & 1 & 3 & 0 & 4 & 2 & 3 & 2 & 3 & 0 & 3 & 0 & 1 & 4 & 26 & $60 \%$ \\
\hline Mean & 4.0 & 2.8 & 1.2 & 4.8 & 0.4 & 2.8 & 2 & 2.4 & 1.6 & 3 & 0.6 & 1.4 & 4 & 31 & $72 \%$ \\
\hline$\%$ of max. score & $67 \%$ & $47 \%$ & $60 \%$ & $80 \%$ & $20 \%$ & $93 \%$ & $100 \%$ & $80 \%$ & $80 \%$ & $100 \%$ & $30 \%$ & $70 \%$ & $100 \%$ & $72 \%$ & \\
\hline
\end{tabular}

$\mathrm{A}_{1}=$ description of research population and selection criteria; $\mathrm{A}_{2}=$ description of cases/controls; $\mathrm{A}_{3}=$ participation rate; $\mathrm{A}_{4}=$ study size; $A_{5}=$ measures against reactivity; $B_{1}=$ validity of memory measure instruments; $B_{2}=$ number of memory aspects measured; $C_{1}=$ validity of quality of life measure instruments; $\mathrm{C}_{2}=$ number of quality of life aspects measured; $\mathrm{D}_{1}=$ data presentation; $\mathrm{D}_{2}=$ corrections for relevant confounders; $\mathrm{D}_{3}=$ description of significant effects and effect sizes; $\mathrm{D}_{4}=$ use of statistical methods.

inclusion criteria (Derouesné et al., 1989; Bazargan and Bazargan, 1997; Commissaris et al., 1998; Derouesné et al., 1999; Verhaeghen et al., 2000). The methodological quality of the studies was moderate to high, considering the mean of 31 out of 43 points (72\%). All identified studies confirmed the existence of a relation between forgetfulness and a lower level of well-being (Derouesné et al., 1989; Bazargan and Bazargan, 1997; Commissaris et al., 1998; Derouesné et al., 1999; Verhaeghen et al., 2000).

One of the five studies confirmed that memory complaints were strongly related to low well-being, but found that symptoms of depression, and not wellbeing, was the unique variable related to severity of memory complaints (Derouesné et al., 1989). Additionally, Derouesné et al. (1999) found that symptoms of anxiety together with well-being was related to subjective memory complaints. The finding that depression and anxiety are related to subjective memory complaints is a plausible finding, because negative affect and mood are often seen as a part of well-being (Felce et al., 1995; Diener et al., 1998). Furthermore, previous research has shown that subjective memory complaints are associated with symptoms of depression (Ponds et al., 1997) and anxiety (Comijs et al., 2002). Thus, symptoms of depression seem to be related to both perceived forgetfulness and quality of life. The relation between forgetfulness and quality of life might therefore be mediated by symptoms of depression.

Another way to explain the relation between subjective memory complaints and diminished wellbeing might be the fear of dementia that is induced by individuals with perceived forgetfulness. Many individuals are afraid that their subjective memory complaints are a sign of early dementia (Commissaris et al., 1994). However, there is no conclusive support that subjective memory complaints are strong predictors of incipient dementia. Whereas several studies failed to find a relationship between subjective memory complaints and objective performances (Bolla et al., 1991; Jorm et al., 1997), others did report an association between subjective memory complaints and diminished cognitive performance (Jonker et al., 2000; Jorm et al., 2001). Therefore, it cannot be precluded that the relation between perceived forgetfulness and low well-being is actually resulting from an incipient neurodegenerative disorder such as Alzheimer's disease. Another explanation for the relation between forgetfulness and quality of life might be that a diminished quality of life is causing forgetfulness, and not that forgetfulness is causing the diminished quality of life. However, more research is needed to determine the causal relation between these two factors.

Overall, all five studies are in line with a possible relationship between memory complaints and a low quality of life. These findings appear to be robust because the five studies are characterized by a wide variety of instruments. One study used life satisfaction scales to measure participants' quality of life (Commissaris et al., 1998), three other studies used well-being questionnaires (Derouesné et al., 1989; Bazargan and Bazargan, 1997; Derouesné et al., 1999) and one study used a life satisfaction scale in combination with a depression scale as a measure of 
well-being (Verhaeghen et al., 2000). Variation was also found in the measurement of subjective memory function, which was measured with subjective memory scales (Derouesné et al., 1989, 1999), memory functioning questionnaires (Bazargan and Bazargan, 1997), and meta-memory scales (Verhaeghen et al., 2000).

Considering the methodological issue of this review, there seems to be a lack of longitudinal studies on the effect of self-reported memory function on the well-being of older individuals. Future research should consist of properly designed studies that focus on the longitudinal effects of memory complaints on well-being. This might give more insight in the causal relation between memory complaints and quality of life. It might be that the memory complaints are not influencing someone's well-being but that poor well-being is causing the subjective complaints. Furthermore, the effect sizes of the results were not profoundly discussed in the studies. More research is needed to give insight in the clinical significance and importance of the relationship between quality of life and subjective memory complaints. Another topic of interest for further research could also be the different impact of a more serious cognitive impairment, such as MCI and dementia, on someone's quality of life. Previous research has shown that an objective cognitive disorder is not always associated with a diminished quality of life, as is reported in several studies (Ready et al., 2004; Comijs et al., 2005; Katsuno, 2005; Selwood et al., 2005). This is contradictory to the expectations of healthy individuals without a cognitive dysfunction (Patrick et al., 1994). The fear of developing dementia, which is often underlying the subjective memory complaints, might have a major impact on quality of life. However, more research is needed before conclusions can be drawn. The findings of the present study emphasize the impact that perceived forgetfulness can have on quality of life. Apparently, individuals with perceived forgetfulness are a population at risk to low well-being. It might, therefore, be important to design health educational activities and psychoeducational interventions for individuals with subjective memory complaints to reduce the memory complaints and improve quality of life.

It should be noted that this review included a relatively small number of articles because few studies were available on the relation between subjective memory function and well-being. However, to our knowledge all published articles on the relation between subjective memory complaints and quality of life were included. We are reasonably confident that we did not miss relevant articles because we searched Pubmed, PsychINFO as well as Embase, made use of a combination of search terms covering a wide range of the field, and the selected articles were hand searched to find additional relevant papers. Because no other literature was available, this review provides a complete overview of the studies concerning forgetfulness and wellbeing. It should also be noted that two studies did not explicitly state that individuals with objective cognitive dysfunction were excluded from the study population (Bazargan and Bazargan, 1997; Verhaeghen et al., 2000). However, it is not probable that participants with dementia or other cognitive dysfunction were present in these studies, because only healthy individuals were investigated in the studies.

In summary, the findings of the five methodologically adequate studies suggest a relation between memory complaints and a lower quality of life of older individuals, even though there is a substantial heterogeneity in the methodology of the studies. This finding emphasizes that memory complaints are related to a negative quality of life. It is therefore important to acknowledge subjective memory complaints as a serious issue. However, more research is needed to explore the relationship between subjective memory complaints and quality of life, especially with regard to the influence of depression and objective memory performance. In addition, further research should be conducted to investigate the longitudinal effect of memory complaints on someone's quality of life in more detail.

\section{REFERENCES}

Bazargan M, Bazargan S. 1997. Self-reported memory function and psychological well-being among elderly African American persons. J Black Psychol 23: 103-119.

Blazer DG, Hays JC, Fillenbaum GG, Gold DT. 1997. Memory complaint as a predictor of cognitive decline: a comparison of African American and White elders. J Aging Health 9: 171184.

Bolla KI, Lindgren KN, Bonaccorsy C, Bleecker ML. 1991. Memory complaints in older adults. Fact or fiction? Arch Neurol 48: 61-64.

Bryan J, Calvaresi E. 2004. Associations between dietary intake of folate and vitamins B-12 and B-6 and self-reported cognitive function and psychological well-being in Australian men and women in midlife. J Nutr Health Aging 8: 226-232.

Capsi A, Elder GH Jr. 1986. Life satisfaction in old age: linking social psychology and history. Psychol Aging 1: 18-26.

Comijs HC, Deeg DJH, Dik MG, et al. 2002. Memory complaints: The association with psycho-affective and health problems and 
the role of personality characteristics. A 6-year follow-up study. $J$ Affect Disord. 72: 157-165.

Comijs HC, Dik MG, Aartsen MJ, et al. 2005. The impact of change in cognitive functioning and cognitive decline on disability, wellbeing, and the use of healthcare services in older persons. Results of Longitudinal Aging Study Amsterdam Dement. Geriatr Cogn Disord 19: 316-323.

Commissaris CJAM, Verhey FRJ, Ponds RWHM, et al. 1994. Patient education about normal forgetfulness and dementia: importance and effects. Patient Educ Couns 25: 163-167.

Commissaris CJAM, Ponds RWHM, Jolles J. 1998. Subjective forgetfulness in a normal Dutch population: possibilities for health education and other interventions. Patient Educ Couns 34: $25-32$.

De Vet HCW, de Bie SE, Verhagen A, et al. 1997. Systematic reviews on the basis of methodological criteria. Physiotherapy 83 : 284-289.

Deeg DJ, Haga H, Yasumura S, et al. 1992. Predictors of tenyear change in physical, cognitive and social function in Japanese elderly Arch Gerontol Geriatr 15: 163-179.

Derouesné C, Alperovitch A, Arvay N, et al. 1989. Memory complaints in the elderly: a study of 367 community-dwelling individuals from 50 to 80 years old. Arch Gerontol Geriatr Suppl 1: $151-163$.

Derouesné C, Lacomblez L, Thibault S, LePoncin M. 1999. Memory complaints in young and elderly subjects. Int J Geriatr Psychiatry 14: 291-301.

Diener E, Suh EM. 1998. Subjective well-being and age: an international analysis. Ann Rev Gerontolog Geriatr 17: 304-324.

Felce D, Perry J. 1995. Quality of life: its definition and measurement. Res Dev Disabil 16: 51-74.

Jonker C, Geerlings MI, Schmand B. 2000. Are memory complains predictive for dementia? A review of clinical and populationbased studies. Int J Geriatr Psychiatry 15: 983-991.

Jorm AF, Christensen H, Korten AE, Henderson AS, Jacomb PA, Mackinnon A. 1997. Do cognitive complaints either predict future cognitive decline or reflect past cognitive decline? A longitudinal study of an elderly community sample. Psychol Med 27: 91-98.

Jorm AF, Christensen H, Korten AE, et al. 2001. Memory complaints as a precursor of memory impairment in older people: a longitudinal analysis over 7-8 years. Psychol Med 31: 441-449.
Katsuno T. 2005. Dementia from the inside: how people with earlystage dementia evaluate their quality of life. Ageing Soc 25: 197214.

Kim KA, Mueller DJ. 1997. Memory, self-efficacy, and adaptability in Korean American older adults: a collective study of four cases. Educ Gerontol 23: 407-423.

Lipsey M, Wilson D. 2001. Practical Meta-Analyses. Sage Publications: Thousand Oaks, CA.

McDougall GJ. 1994. Predictors of metamemory in older adults. Nurs Res 43: 212-218.

McDougall GJ, Montgomery KS, Eddy N, et al. 2003. Aging memory self-efficacy: elders share their thoughts and experience. Geriatr Nurs 24: 162-168.

Neri M, Andermarcher E, Pradelli JM, Salvioli G. 1995. Influence of a double blind pharmacological trial on two domains of wellbeing in subjects with age associated memory impairment. Arch Gerontol Geriatr 21: 241-252.

Patrick DL, Starks HE, Cain KC, et al. 1994. Measuring preferences for health states worse than death. Med Decis Making 14: 918.

Ponds RW, Commissaris KJ, Jolles J. 1997. Prevalence and covariates of subjective forgetfulness in a normal population in The Netherlands. Int J Aging Hum Dev 45: 207-221.

Ready RE, Ott BR, Grace J. 2004. Patient versus informant perspectives of Quality of Life in Mild Cognitive Impairment and Alzheimer's disease. Int J Geriatr Psychiatry 19: 256-265.

Selwood A, Thorgrimsen L, Orrell M. 2005. Quality of life in dementia; a one-year follow-up study. Int J Geriatr Psychiatry 20: 232-237.

Starr JM, Deary IJ, Macintyre S. 2003. Associations with successful ageing in the 'Healthy Old People in Edinburgh' cohort: being well, fit and healthy. Aging Clin Exp Res 15: 336-342.

Steen G, Hagberg B, Johnson G, Steen B. 1987. Cognitive function, cognitive style and life satisfaction in a 68-year-old male population. Compr Gerontol [B] 1: 54-61.

Verhaeghen P, Geraerts N, Marcoen A. 2000. Memory complaints, coping, and well-being in old age: a systemic approach. Gerontologist 40: $540-548$.

Wolters G, Bemelmans KJ, Spinhoven P, et al. 1996. Immediate and intermediate-term effectiveness of a memory training program for the elderly. J Cog Rehab 14: 16-22. 


\section{APPENDIX 1}

List of criteria for the methodological assessment of observational research.

\begin{tabular}{lrrr}
\hline Criteria & Obtainable points & Score \\
\hline A $\quad$ Research population and design & 22 & & - \\
1. Have the research population and the applied inclusion & 6 &
\end{tabular}
and exclusion criteria been described?

2. Have the differences and similarities between cases and controls been described? For example education, age, sex, social-economic background, self-referral/Are the differences

Only cases in the study (well described): 3 between the groups described?

3. What is the participation rate of the study?/How many summoned people actually participate in the research?/Have measures to prevent selection bias been taken?

4. Is the study size of the research sufficient?

5. Have measures to prevent reactivity been taken?

Cases and controls (well described): 6

Participation rate $50-80 \%: 1$

Participation rate $>80 \%: 2$

Total $n>56: 2$

Total $n>128: 4$

Total $n>788: 6$

Power analysis performed: 6

\section{2}

B Measurement of memory complaints

5

1. Has the validity and reliability of the measurement

instruments been determined (in an earlier or in the same article)?

2. Are several aspects of memory complaints measured?

C Measurement of quality of life

1. Has the validity and reliability of the measurement

instruments been determined (in an earlier or in the same article)?

2. Are several aspects of quality of life measured?

D Analysis and data presentation

1 . Are the data clearly and fully presented?

2. Has the analysis been corrected for relevant 'confounders'?

3. Has, besides the statistical significance, the clinical significance/effect size also been described?

4. Have statistical methods been used in an appropriate manner? 